International Journal of Current Advanced Research

ISSN: O: 2319-6475, ISSN: P: 2319 - 6505, Impact Factor: SJIF: 5.995

Available Online at www.journalijcar.org

Volume 6; Issue 5; May 2017; Page No. 3905-3908

DOI: http://dx.doi.org/10.24327/ijcar.2017.3908.0393

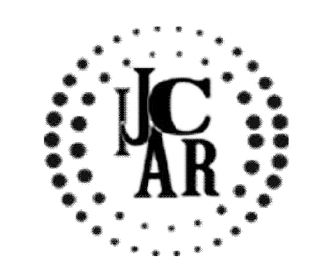

Research Article

\title{
EFFICACY OF CITRIC ACID AND CHLORHEXIDINE AS DENTURE CLEANSERS AGAINST CANDIDA ALBICANS - AN IN VITRO STUDY
}

\author{
Danalakshmi J,. Preetham Prasad Nittla,. Muralidharan and Shabana Bowsiya
}

Saveetha Dental College, Saveetha University, Chennai

Article History: Received $17^{\text {th }}$ February, 2017, Received in revised form $20^{\text {th }}$ March, 2017 Accepted $18^{\text {th }}$ April, 2017 , Published online $28^{\text {th }}$ May, 2017

\section{INTRODUCTION}

A complete denture is defined as a dental prosthesis, which replaces the entire dentition and associated structures of the maxilla and mandible (1). A denture becomes susceptible to infections due to the biofilm formed on its surface on placement in the oral environment (2). Almost 11-67\% of the denture wearers have reported with Denture stomatitis (3). Candida is one of the chief causes for denture- induced stomatitis due toit's adherence to denture surface and oral tissues, its ability to form biofilms and resistance to antifungal agents(4). Decreased flow of oxygen and saliva caused by the denture results in local acidic and anaerobic microenvironment of the underlying tissues that favours yeast growth. This ultimately increases the prevalence of Candida by $60-100 \%$ in denture wearers (5). Candidiaalbicans that manifest in the biofilm, an important contributor to the pathogenesis of denture stomatitis, is essential for the instalment and maintenance of denture stomatitis (6).

Dentures can be cleaned mechanically, chemically or through a combination of both these methods. Mechanical methods comprises of brushing, and ultrasonic treatment uses ultrasonic cleansers (7). Chemical methods include soaking the dentures in commercial (peroxides, acids, mouth washes and enzymes) or household (hypochlorides, sodium chloride vinegar) products (8). These chemicals are easy to use and can easily reach undercuts of the denture base which are otherwise overlooked during other denture cleansing methods. One of the main disadvantages of mechanical denture cleansing methods is abrasion due to brushing is overcome by chemical methods as the acrylic resins surface roughness remains unchanged and the surfaces are less susceptible to biofilm accumulation (9).

Citric acid denture cleanser is available as a concentrated solution, which can be used 1:5 dilution daily or 1:8 dilution weekly after proper dilution (as indicated by the manufacturer).

*Corresponding author: Danalakshmi J

Saveetha Dental College, Saveetha University, Chennai
This cleanser acts as a chemotherapeutic agent that can effectively disrupt biofilms through a sequestering mechanism with calcium ions. This mechanism allows citric acid to break calcium bridges and subsequently disrupt the biofilm matrix, which may lead to anti-biofilm activity. Although citric acid cleansers used continuously for 3 months showed adverse effects with greater ion release from $\mathrm{Co}-\mathrm{Cr}$ alloys when used to decontaminate implant surfaces, no harmful effects have been demonstrated with denture materials in general. Therefore, citric acid cleansers might be suitable for removable dentures and orthodontic appliances and for removing biofilms and preventing their recolonization (10).

Chlorhexidine has a broad spectrum of antimicrobial activity for a number of organisms including Candida and is used as a topical therapeutic supplement $(11,12)$. Also candidal adhesion to biological and inert surfaces can be inhibited by chlorhexidine (13). Chlorhexidine acts as a fungicide and has fungistatic action which results in coagulation of nucleoproteins and escape of cytoplasmic components through the plasmolemma due to cell wall changes (14).

There are many known denture disinfectants such a EDTA, sodium hypochlorite, sodium perborate, povidone iodine, hydrogen peroxide, etc. (15). In this study we study the effectiveness of citric acid and chlorhexidine as denture cleansers.

\section{Methodology}

The effect of disinfectant was tested by two methods. One was by contamination of denture bases with candida suspension and the second method was by testing the effect of the standardized concentration of disinfectant in a broth.

\section{Sample fabrication}

A total of 40 heat-polymerized acrylic denture strips were obtained from a wax pattern with a standardized dimension of $5 \times 1 \mathrm{~cm}$. The wax pattern was invested with dental stone (type III gypsum) in a metallic flask. After the setting of dental stone, dewaxing is done by immersing the flask in a water bath at a temperature of $70-80^{\circ} \mathrm{C}$ for about 10 minutes (18). Heat-polymerized acrylic resin was mixed according to the manufacturers recommendation and packed into the mold at the dough stage. The metal flask was then closed and subjected to a short curing cycle at $74^{0} \mathrm{C}$ for 2 hours followed 
by a terminal boiling at $100^{\circ} \mathrm{C}$ for 1 hour (19). On completion of curing cycle, the flask was allowed to completely cool before opening and the denture sample was obtained. The denture strips of $5 \times 1 \mathrm{~cm}$ dimension were checked for any imperfections. The cameo surface of the strips were sandpapered and polished (19). On completion of processing, the strips were packed and autoclaved.

\section{Contamination of specimen}

40 heat cured denture acrylic denture strips were selected and sterilized by autoclaving at $15 \mathrm{lbs}$ for 30 minutes. These denture strips were immersed in sterilized uricol containers containing $50 \mathrm{ml}$ of sterilized artificial saliva. A Candida albicans suspension was made to the turbidity matching 0.5 Mcfarland standard by immersing for 30 minutes. $100 \mu \mathrm{l}$ of suspension is added to the artificial saliva and well shaken to ensure a good mix. The denture strips in the above suspension was incubated for 3 days at $37^{\circ}$ Celsius after which it was taken out, and cleaned with mineral water and then immersed in $50 \mathrm{ml}$ of disinfectant and kept for 6 hours. A subculture was made on Brain Heart Infusion agar and incubated for 24 hours.

\section{Preparation of disinfectants}

Commercially available $20 \%$ citric acid and $2 \%$ chlorhexidinewere used as denture cleansing agents in this study. Saline was taken as the negative control and $0.2 \%$ chlorhexidine containing commercially available mouthwash was taken as the positive control. After incubation for 48 hours, the denture samples were washed in drinking water and placed in a sterile container containing denture cleansing agent. 10 denture samples were placed in each denture cleansing agent $(20 \%$ citric acid and chlorhexidine $2 \%)$. The denture samples were left in the denture cleansing agent for 6 hours.

\section{Culture preparation}

After 6 hours, a swab was taken from the rough surface of the denture base sample and streak on the SDA plate. Repeat this for all the denture base samples. Incubate the SDA plates for 24 hours. After 24 hours, the growth pattern of Candida albicans was observed.

\section{Broth culture}

The disinfectant material is taken in a standardized concentration in 5 curettes of $1 \mathrm{ml}$ each, the candida suspension which was made with turbidity matching 0.5 McFarland standard is taken and 10 microliter of the suspension is added to disinfectants taken in cuvette. It was allowed to react for 6 hours at room temperature. After the 6 hour period 10 microliter of this preparation was transferred to saborauds dextrose agar and incubated for 12 hours at 37 degrees Celsius. The test was done along with a positive and a negative control.

\section{Experimental and control groups}

Four groups each containing contaminated specimen of 10 were assigned to various disinfectants.

Group I: Saline (control)

Group 2: Citric acid 20\%

Group 3: Chlorhexidine $0.2 \%$
Group 4: Chlorhexidine2\%

Table 1

\begin{tabular}{ccc}
\hline Denture Cleansing agent & Positive & Negative \\
\hline Citric acid $20 \%$ & 3 & 7 \\
Chlorhexidine $2 \%$ & 0 & 10 \\
Saline & 10 & 0 \\
Chlorhexidine $0.2 \%$ & 4 & 6 \\
\hline
\end{tabular}

\section{RESULTS}

The results obtained from both methods were consistent with each other.When tested against the two controls, it was found that both disinfectants had effective disinfecting properties against Candida albicans.

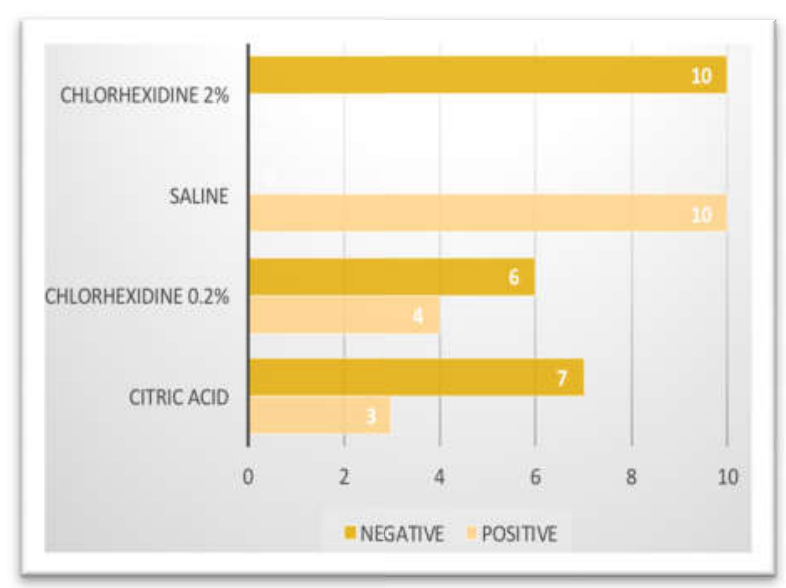

Fig 1

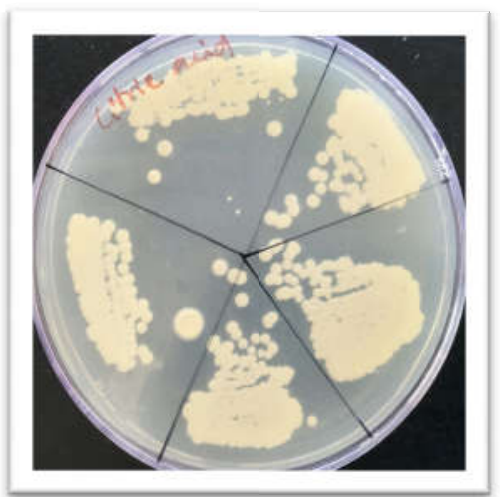

Citric acid

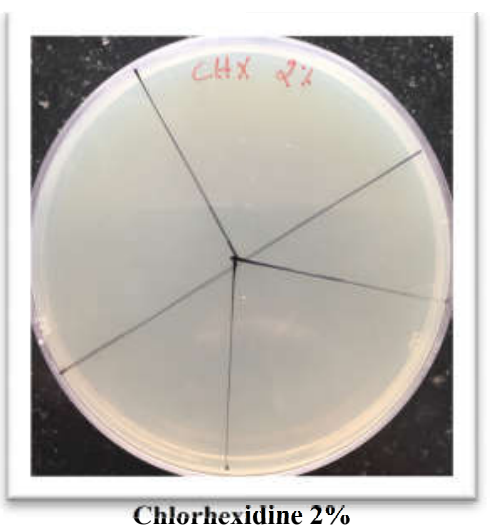



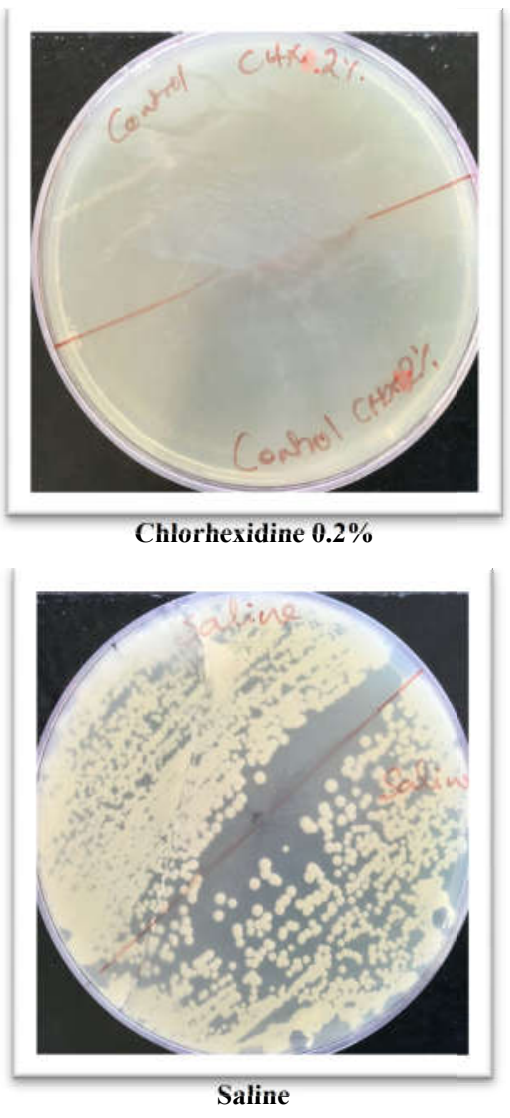

\section{DISCUSSION}

Citric acid is a chemotherapeutic agent with an increased potential fin eliminating biofilms in vitro, although complete removal of the biofilms is not reported $(16,17)$. The current study revealed a $40 \%$ positive result for Candida when $20 \%$ citric acid was used as a denture cleanser. One study showed that although the number of viable cells immediately after treating with citric acid was null, it was confirmed that a residual biofilm was present (10). Citric acid has showed reduction in the viability of Candida albicans immediately after treatment but cannot completely cleanse the denture surface or prevent the recolonisation of the candidial biofilm (10). Citric acid does not affect the basal layers of the biofilm which is protected by an extra cellular matrix and hence leads to the recolonisation of Candida after 48 hours. Citric acid will thus not be effective in eliminating a biofilm of Candida or prevent their recolonisation on a single exposure $(18,19)$. Citric acid acts by disrupting the biofilms but it does completely remove them. This finding suggests that citric acid can be an effective complementary method for biofilm removal after the debris are removed from the denture surface namely by using a mechanical method.Thus, citric acid is expected to present more consistent effects on biofilm elimination when used as an adjunct tomechanical method, such as brushing, to completely cleanse the dentures $(16,17,20)$.

Candida species might express increased virulence in addition to adherence in biofilms formed and hence are more resistant to antigungals $(21,22)$. Studies showed that microorganism present in the biofilm have an increase in resistance to antimicrobial agents up to 500 times that of planktonic organisms $(23,24)$. Hence it is very essential to employ new treatment options for Candidiasis though chlorhexidine is not the first line of treatment against Candida (25). Chlorhexidineacts by binding to the negatively charged surfaces like the epithelial cells because it is a cationic biguanide (25) and it disrupts the adhesion abilities of Candida which isan important virulent factor (13). Chlorhexidine's effect at a macroscopic level shows disruption of adherence and at cellular level indicates the effect of chlorhexidine on the structural viability and intergrity of Candida biofilms (26). At low doses chlorhexidine damages the cellular transport of bacterial cells by creating pores in the cell membrane and at higher doses will cause cell death by penetrating into the microbial cell (27). Studies prove this destruction capacity of chlorhexidine where the number of viable cells in the Candida biofilm were significantly reduced after exposure to chlorhexidine (25). The current study tested chlorhexidine of 2 different concentrations where chlorhexidine $0.2 \%$ had 4 strips that were positive for Candida whereas the chlorhexidine $2 \%$ had no strips positive for Candida (Table 1.1) indicating the effectiveness of Chlorhexidine against Candida biofilms at higher concentrations.

In the present study citric acid $20 \%$ had a success rate of $70 \%$ in eliminating Candida biofilms. Previous studies conducted had similar results where complete removal of Candida was seen as an immediate effect to citric acid exposure. However these studies indicated the recolonisation of Candida in 48 hours (10). This shows that citric acid has to be used as a complementary agent in denture cleansing as it can remove biofilms though not permanently. Chlorhexidinethat was tested in the present study revealed results based on the concentration where chlorhexidine $0.2 \%$ had a success rate of $60 \%$, chlorhexidine $2 \%$ had a success rate of $100 \%$ as all the strips were negative for Candida. This is in accordance with studies that showed the different mechanisms of action of varying chlorhexidine concentrations (27). Hence from this study we can conclude that both the disinfectants are effective in eliminating Candida biofilms. Citric acid can be used either in combination with mechanical methods of brushing or coupled with another chemical disinfectant that can complement its properties. Similarly chlorhexidine can be included in a comparatively higher concentrations in denture cleansers to prevent Candidial manifestations as Candida have developed resistance to the commonly used antifungals. However large scale studies regarding the efficacy of such methods is required to establish a reliable result.

\section{CONCLUSION}

Hence of the two chemical disinfectants studied, three strips showed positive candidial growth for Hydrogen peroxide and none of the strips showed positive candidial growth for Chlorhexidine $2 \%$ concluding that both agents are effective denture cleansers.

\section{References}

1. Sharry JJ. Complete Denture Prosthodontics, 3rd ed. New York: Blakiston; 1974: 191-210.

2. The Health and Social Care Information Centre. Adult dental health survey 2009. London: Department of Health, 2010.

3. Theilade E, Budtz-Jorgensen E. Predominant cultivable microflora of plaque on removable dentures 
in patients with denture induced stomatitis. Oral Microbiol Immunol 1988; 3:8-13

4. Silva M, Vergani C, Giampaolo E, Neppelenbroek K, Spolidorio D, Machado A. Effectiveness of microwave irradiation on the disinfection of complete dentures. Int J Prosthodont 2006; 19:288-293

5. Fungal biofilms and related infections advances in Microbiology, Infectious Diseases and Public Health Volume 3 page 89

6. Dorey JL, Blasberg B, MacEntee MI, Conklin RJ. Oral mucosal disorders in denture wearers. JProsthetDent. 1985;53(2):210-3

7. Sanita' P, Vergani C, Giampaolo E, Pavarina A, Machado A. Growth of Candida species on complete dentures: effect of microwave disinfection. Mycoses 2009; 52:154-160

8. Senna P, Sotto-Maior B, Silva W, Del Bel Cury A. Adding denture cleanser to microwave disinfection regimen to reduce the irradiation time and the exposure of dentures to high temperatures. Gerodontology 2013; 30:26-31

9. Senna P, da Silva W, Cury A. Denture disinfection by microwave energy: influence of Candida albicans biofilm. Gerodontology 2012; 29:186-191

10. Fernanda Faot, Yuri WanderleyCavalcanti, Martinna de Mendonça e Bertolini, Luciana de Rezende Pinto, Wander José da Silva, Altair Antoninha Del Bel Cury.Efficacy of citric acid denture cleanser on the Candida albicans biofilm formed on poly (methyl methacrylate): effects on residual biofilm and recolonization process. BMC Oral Health 2014, 14:77

11. Suci PA, Tyler BJ. Action of chlorhexidine digluconate against yeast and filamentous forms in early-stage Candida albicans biofilm. Antimicrob Agents Chemother. 2002; 46: 3522-31.

12. Torres SR, Peixoto CB, Caldas DM, Akiti T, Barreiros MGC, Uzeda $\mathrm{M}$, et al. A prospective randomized trial to reduce Candida spp. colonization in patients with hyposalivation. Braz Oral Res. 2007; 21: 182-7.

13. Ellepola ANB, Samaranayake LP. Adjunctive use of chlorhexidine in oral candidosis: a review. Oral Dis. 2001; 7: 11-7.

14. Bobichon H, Bouchet P. Action of chlorhexidine on budding Candida albicans: screening and transmission electron microscopic study. Mycopathologia. 1987; 100: 27-35.

15. D.C. Jagger, A. Harrison. Denture cleansing - the best approach. Braz Dent J. 1995;178:413-417

16. Ntrouka VI, Slot DE, Louropoulou A, Van derWeijden F: The effect of chemotherapeutic agents on contaminated titanium surfaces: a systematic review. Clin Oral Implants Res 2011, 22:681-690.
17. Ntrouka V, Hoogenkamp M, Zaura E, van derWeijden F: The effect of chemotherapeutic agents on titaniumadherent biofilms. Clin Oral Implants Res 2011, 22:1227-1234.

18. Gomes PN, da Silva WJ, Pousa CC, Narvaes EA, Del Bel Cury AA: Bioactivity and cellular structure of Candida albicans and Candida glabrata biofilms grown in the presence of fluconazole. Arch Oral Biol 2011, 56:1274-1281.

19. Nikawa H, Hamada T, Yamashiro H, Kumagai H: A review of in vitro and in vivo methods to evaluate the efficacy of denture cleansers. Int J Prosthodont 1999, 12:153-159.

20. Mouhyi J, Sennerby L, Pireaux JJ, Dourov N, Nammour S, Van Reck J: An XPS and SEM evaluation of six chemical and physical techniques for cleaning of contaminated titanium implants. Clin Oral Implants Res 1998, 9:185-194.

21. Chandra J, Kuhn DM, Mukherjee PK, Hoyer LL, McCormick T, Ghannoum MA. Biofilm formation by the fungal pathogen Candida albicans: Development, architecture and drug resistance. $J$ Bacteriol. 2001; 183: 5385-94.

22. Lamfon H, Porter SR, McCullought M, Pratten J. Susceptibility of Candida albicans biofilms grown in a constant depth film fermentor to chlorhexidine, fluconazole and miconazole: a longitudinal study. J Antimicrobial Chemother. 2004; 53: 383-5.

23. Makihira S, Nikawa H, Tamagami M, Hamada t, Samaranayake LP. Differences in Candida albicans adhesion to intact and denature type I collagen in vitro. Oral Microbiol Immunol. 2002; 17: 129-31.

24. Meiller TF, Kelley JI, Jabra-Rizk MA, DePaola LG, Baqui A, Falker WA. In vitro studies of the efficacy of antimicrobials against fungi. Oral Surg Oral Med Oral Pahol Oral RadiolEndod. 2001; 91: 663-70.

25. Fernanda Campos Machado, Maristela Barbosa Portela, Amanda Carneiro da Cunha, Ivete Pomarico Ribeiro de Souza, Rosângela Maria de Araújo Soares, Gloria Fernanda Barbosa de Araújo Castro. Antifungal activity of chlorhexidine on Candida spp. Biofilm. Rev Odontol UNESP, Araraquara., 2010; 39(5): 271-275

26. MacNeill S, Rindler E, Walker A, Brown AR, Cobb CM. Effects of tetracycline hydrochloride and chlorhexidinegluconate on Candida albicans. An in vitro study. J ClinPeriodontol. 1997; 24: 753-60.

27. Franco Neto CA, Parolo CCF, Rösing CK, Maltz M. Comparative analysis of the effect of two chlorhexidinemouthrinses on plaque accumulation and gingival bleeding. Braz Oral Res. 2008; 22: 13944.

\section{How to cite this article:}

Danalakshmi J et al (2017) 'Efficacy Of Citric Acid And Chlorhexidine As Denture Cleansers Against Candida Albicans - An In Vitro Study', International Journal of Current Advanced Research, 06(05), pp. 3905-3908.

DOI: http://dx.doi.org/10.24327/ijcar.2017.3908.0393 